\title{
Nursing diagnoses in patients with morbid obesity
}

\author{
Lidiany Galdino Felix ${ }^{1}$, M. J. G. O. Soares ${ }^{2}$, M. M. L. Nóbrega ${ }^{3}$, F. A. L. Medeiros ${ }^{4}$ \\ 1. Academic Unit of Health Sciences, Federal University of Campina Grande, Campina Grande, Paraíba, Brazil. \\ 2. Department of Clinical Nursing, surgical and Administration. Federal University of Paraíba, J oão Pessoa, Paraíba, Brazil. \\ 3. Department of Public Health Nursing and Psychiatry, Federal University of Paraíba, João Pessoa, Paraíba, Brazil. \\ 4. Department of Nursing at the State University of Paraíba. Campina Grande, Paraíba, Brazil.
}

Correspondence: Lidiany Galdino Felix. Address: João Francisco da Mota street, 450 apt. 403 Catolé, Brazil. Telephone: 55-838-895-1061. Email: lidiany_felix@hotmail.com.

Received: January 31, 2013

DOI : $10.5430 /$ jnep.v3n12p27
Accepted: April 23, $2013 \quad$ Online Published: May 7, 2013

URL: http://dx.doi.org/10.5430/jnep.v3n12p27

\section{Abstract}

Background: The identification of nursing diagnoses in patients with morbid obesity contributes to the planning of interventions, through a systematized and scientifically grounded care. This study aimed to identify nursing diagnoses in morbidly obese patients treated in outpatient care using the International Classification for Nursing Practice (ICNP®), version 2.0.

Methods: This is a cross-sectional and descriptive study, with a quantitative approach, carried out through the application of an instrument based on Orem's Self-Care Theory. The sample consisted of 31 patients treated at the gastroenterology outpatient unit of a university hospital in the city of Joao Pessoa, Paraiba, Brazil.

Results: One identified 12 nursing diagnoses, standing out: impaired adaptation (90.3\%); impaired socialization (67.7\%); adherence to the physical exercise regime (58.4\%); impaired sleep pattern (58.4\%); functional dyspnea (58.1\%); and adherence to the medication regime (51.6\%).

Conclusions: Knowing the nursing diagnoses of people with morbid obesity undergoing outpatient care allows nurses to plan the individual care provided to this clientele, and contribute to the development and maintenance of self-care abilities. One hopes this study can contribute to the development of scientific practices in the process of caring for patients with morbid obesity, in order to encourage and improve the production of further researches addressing nursing care in this growing practice field.

\section{Key words}

Nursing, Nursing diagnosis, Morbid obesity, Self-care

\section{I ntroduction}

Obesity is a complex disease characterized by excessive accumulation of fat in the body, which causes damage to the individual's health, besides being regarded, nowadays, as a pandemic both in developed and developing countries ${ }^{[1]}$. According to the World Health Organization (WHO), there're more than one billion adults with overweight worldwide; out of these, at least 300 million are obese people. In Brazil, numbers provided by the Ministry of Health show that, in $2010,48.1 \%$ of adults were overweight and $15 \%$ of the population was already considered obese. Every year, more than 80 thousand deaths are recorded as a result of obesity in the country ${ }^{[2]}$. 
Due to the complexity involved in the situation of being obese, as well as the difficulties these people face to follow a conservative treatment and have a positive outcome from it ${ }^{[3]}$, the bariatric surgery has been regarded as the primary treatment for weight reduction and improvement of comorbidities associated with obesity ${ }^{[4]}$.

Brazil takes the second place in the world with regard to the number of bariatric surgeries performed; this surgical procedure started being carried out on a larger scale in the country since 2000. The number of bariatric surgeries increased from 1,773 in 2003 to 5,332 in 2011, representing an increase over 300\%. According to data from the Ministry of Health, only through the Unified Health System (SUS), more than 1,280 bariatric surgeries were performed in the first quarter of $2012^{[5]}$.

As the number of bariatric patients increases and surgical procedures become safer and more efficient ${ }^{[6]}$, one expects that the number of patients considering bariatric keeps increasing over the next years, making this kind of surgery one of the most frequently performed procedures ${ }^{[7]}$.

Furthermore, the treatment of obesity requires a dedicated multidisciplinary team, in order to achieve consistent and sustainable outcomes. Surgeons, dietitians, psychologists, nurses, and bariatricians must carefully orchestrate each step in the process, for providing the patient who undergoes a bariatric surgery with an optimal care ${ }^{[8]}$.

As members of the multidisciplinary team, nurses are challenged when caring for bariatric patients, because the tasks require increased time and additional skills for handling them ${ }^{[9]}$. A nurse should be able to evaluate the patient and work along with the surgical team for developing a care plan which aims to promote safety and result in positive outcomes for the obese patient ${ }^{[10]}$.

Despite the growing trend of obesity and its impact on nursing care, there's a lack of researches in the nursing field aimed at the care for obese patients ${ }^{[7]}$. To provide the obese patient with an adequate and systematized care, the nurse needs to use his theoretical knowledge and associate it with practice. This requires knowledge on the nursing theories, in order to use the most appropriate theoretical model for implementing the nursing process ${ }^{[11]}$ to care for the obese patient.

There are several ways to work out the nursing process. One of them is using the nursing diagnosis (a step of the nursing process), according to the International Classification for Nursing Practice (ICNP ${ }^{\circledR}$ ), so that nursing is able to standardize its diagnoses on a worldwide basis ${ }^{[12]}$.

ICNP ${ }^{\circledR}$ is a classification system created by the International Council of Nurses (ICN), in 1989, which aims to standardize a universal language for nursing; its use in nursing practice promotes an accurate and consistent documentation of care, providing data for decision making and for evaluating the quality of care, besides providing patients with continued care $^{[13]}$.

Given that the identification of nursing diagnoses in patients with morbid obesity will contribute to the planning of interventions, through a systematized and scientifically grounded care, this study aimed to identify the nursing diagnoses in morbidly obese patients treated in outpatient care, using ICNP®, version $2.0^{[14]}$.

\section{Methods}

This is a descriptive and exploratory study with a quantitative approach, carried out in an outpatient gastroenterology unit at a university hospital in the city of João Pessoa, Paraíba, Brazil.

The criteria used for inclusion of patients were: age 18 or older, legally able to be in accordance with Brazilian law, be physical and emotional condition to answer questions and willingness to participate. The sample was consisted of 31 morbidly obese patients who were undergoing outpatient treatment, within the period from April to June 2009. 
The research was approved by the Research Ethics Committee of Universidade Federal da Paraíba (UFPB). Data collection was conducted through interviews supported by a form specifically designed for this purpose, which was structured having Orem's Self-Care Theory ${ }^{[15]}$ as a basis; it consisted of open and closed questions, aimed at the identification of the requirements of universal self-care, development, and deviation from health, and organized into four parts, namely:

1) Identification, including the name, medical record number, and socio-demographic data of respondents, such as address, age, religion, marital status, birthplace, profession, educational level, and family income, besides the number of previous consultations and the date of surgery;

2) Universal self-care requirements, addressing the demands of oxygenation, nutrition and hydration, elimination and excretion, rest and physical activity, loneliness and social interaction, prevention of risks to health and well-being, and health promotion practices;

3) Self-care requirements, containing the identification of changes related to the emergence of obesity and information on current diseases associated with obesity; and

4) Self-care requirements in deviations from health, in which one sought information on the main consequences of obesity for the patients' lives, previously performed treatments, and currently used medicines.

Data collection instruments were numbered and the variables contained therein were coded and entered into a database, constructed in Word for Windows. After this step, the data were grouped according to the requirements for self-care. To prepare the diagnostic statements, ICN, based on ISO 18104, recommends that the following guidelines should be used: compulsorily include a term from the Focus axis and a term from the Judgment axis; include additional terms, as needed, from the Focus and Judgment axes, and the other axes of the Seven Axes Model of ICNP®, version 2.0 ${ }^{[14]}$.

The data were analyzed using descriptive statistics, through the software Microsoft Excel; the results were presented in the form of absolute and relative frequencies and, then, discussed under the light of literature.

\section{Results}

Out of the 31 participants in the research, 29 (93.5\%) had grade III obesity (BMI $\left.>40 \mathrm{~kg} / \mathrm{m}^{2}\right), 1$ (3.2\%) had grade II obesity (BMI between 35 and $39.9 \mathrm{~kg} / \mathrm{m}^{2}$ ), and 1 (3.2\%) had class I obesity (BMI between 30 and $34.9 \mathrm{~kg} / \mathrm{m}^{2}$ ). Out of those who had grade III obesity, 9 (29\%) had a BMI between 40 and $45.9 \mathrm{~kg} / \mathrm{m}^{2}, 13$ (41.9\%) had a BMI between 46 and $50.9 \mathrm{~kg} / \mathrm{m}^{2}$, and 7 (22.5\%) had a BMI > $51 \mathrm{~kg} / \mathrm{m}^{2}$.

One observed that $71.0 \%$ of patients treated at the outpatient unit were from the city of João Pessoa and $77.4 \%$ were women. The prevalent age group among men and women ranged from 26 to 40 years (74.2\%). Regarding marital status and educational level, 14 (45.2\%) were single and 15 (48.4\%) had complete high school. Besides, 13 (41.9\%) had a family income up to 1 minimum wage and 23 (74.1\%) had some sort of occupation, with a prevalence of clerks, 5 (16.1\%).

The evaluation of self-care demands presented by respondents provided the basis for identifying the nursing diagnoses, according to Orem's Conceptual Model ${ }^{[15]}$. In order to direct the proposed methodology towards the definition of diagnostic reasoning using ICNP ${ }^{\circledR}$, version $2.0^{[14]}$, in morbidly obese people, the self-care demands are presented in Table 1 , and, then, the resulting nursing diagnoses.

One identified 12 nursing diagnoses. The average of nursing diagnoses per participant was 5.8. The diagnoses presenting a > 50\% frequency were: impaired adaptation (90.3\%); impaired socialization (67.7\%); adherence to the physical exercise regime (58.4\%); impaired sleep pattern (58.4\%); functional dyspnea (58.1\%); and adherence to the medication regime (51.6\%). 
Table 1. Distribution of nursing diagnoses using ICNP®, version 2.0. João Pessoa, Paraíba, Brazil, 2009.

\begin{tabular}{|c|c|c|c|}
\hline \multirow{2}{*}{ Self-care demands } & \multicolumn{2}{|c|}{ Frequency } & \multirow{2}{*}{ Nursing diagnoses (ICNP $®$, version 2.0) } \\
\hline & $\mathbf{N}$ & $\%$ & \\
\hline \multicolumn{4}{|l|}{ Universals } \\
\hline & 18 & 58.1 & - Functional dyspnea \\
\hline & 09 & 29.0 & - Low fluid intake \\
\hline & 15 & 48.4 & - Excessive food intake \\
\hline & 11 & 35.4 & - Impaired intestinal elimination pattern \\
\hline & 14 & 45.2 & - Impaired exercise pattern \\
\hline & 17 & 54.8 & - Adherence to the physical exercise regime \\
\hline & 17 & 54.8 & - Impaired sleep pattern \\
\hline & 21 & 67.7 & - Impaired socialization \\
\hline & 11 & 35.5 & - Impaired health seeking behavior \\
\hline Development & 28 & 90.3 & - Impaired adaptation \\
\hline \multirow{2}{*}{ Deviations from health } & 16 & 51.6 & - Adherence to the medication regime \\
\hline & 10 & 32.3 & - Lack of knowledge on surgery \\
\hline
\end{tabular}

\section{Discussion}

In Brazil, one observes the existence of several studies carried out in order to identify nursing diagnoses in patients with various chronic diseases ${ }^{[11,16-19]}$, however, there're few studies focused on the population with morbid obesity ${ }^{[20,21]}$.

However, research and the use of nursing theories are the appropriate means for establishing the primary focus of nursing care ${ }^{[18]}$. Thus, for people with morbid obesity, we chose to use Orem's Conceptual Model, due to the fact that this theory stresses the importance of client's commitment to self-care, encouraging him to participate in an active way in his recovery. Furthermore, it's one of the models which can drive nursing care actions and respond to the needs of patients with chronic diseases, such as obesity, facilitating the planning of nursing care for these patients ${ }^{[20]}$.

One found out that the average number of nursing diagnoses per participant was 5.8. This result shows the diversity of self-care demands identified in patients with morbid obesity. It's worth highlighting that, out of the 12 nursing diagnoses identified, 9 refer to universal self-care demands, 1 to development demands, and 2 to the deviations from health demands.

The analysis of obtained data revealed that 18 (58.1\%) had the nursing diagnosis functional dyspnea, based on the complaint of breathlessness when walking and performing household tasks.

Obesity increases the risk for respiratory complications after an abdominal surgery ${ }^{[22]}$. Patients who undergo bariatric surgery are at risk for postoperative respiratory complications, since intra-thoracic and abdominal fat may restrict lung expansion and decrease reserve volumes. Respiratory complications may also occur as a result of anesthesia or the use of opioids for postoperative pain management. The respiratory function should be periodically evaluated using pulse oximetry; some patients may require continued monitoring. Encouraging cough and deep breathing is essential to prevent atelectasis and pneumonia ${ }^{[23]}$.

Evidence of poor water intake for daily needs was observed in $29.0 \%$ of reports and it constituted the nursing diagnosis impaired water intake. Low water intake may also be worsened by intense sweating, usual in obese patients. This diagnosis was also found in mastectomy women ${ }^{[11]}$. 
Regarding food intake, through the reports of patients on their feeding routine (breakfast, morning snack, lunch, afternoon snack, and dinner), one found out that 15 (48.4\%) respondents had the nursing diagnosis excessive food intake, showing that almost half of the sample lacked a balanced diet, consuming an excessive amount of food per meal, besides consuming high-calorie snacks instead of regular meals.

Learning to eat properly, opting for healthy foods, is a crucial action to achieve and maintain proper weight. A healthy diet for everyone with overweight and obesity aims to improve well-being, enable health protection, as well as prevent and control comorbidities, allowing the person to reach proper weight ${ }^{[24]}$.

In the excretion/elimination assessment, 11 (35.4\%) respondents had the nursing diagnosis Impaired intestinal elimination pattern, due to frequent episodes of diarrhea and constipation.

In the context of physical activities practice, 17 (54.8\%) had the nursing diagnosis Adherence to the physical exercise regime, by performing some physical activity, such as walking, weight training, and water aerobics; 14 (45.2\%) stated they don't practice any kind of physical activity, due to lack of time, laziness, or health problems, resulting in the nursing diagnosis impaired exercise pattern.

Regular physical activity practice combined to a healthy feeding promotes a decrease in body weight greater than healthy feeding alone, besides increasing fat loss, preserving lean body mass, and decreasing the deposition of visceral fat ${ }^{\text {[24] }}$.

The nursing diagnosis impaired sleep pattern was observed in 17 (54.8\%) respondents, as evidenced by reports of insomnia, restlessness during sleep, or reduced number of sleeping hours per day.

Impaired socialization was the nursing diagnosis of 21 (67.7\%) patients. This diagnosis is related to the lack of social activities due to lack of mood and time, fatigue, and discouragement by obesity. The vast majority of participants (90.3\%) reported having a good relationship with family and friends.

Obese patients usually demonstrate low self-esteem and limited socialization. Restriction in daily life was a general experience reported by respondents. Most obese patients experienced a restricted life with regard to family, friends, and society. An easy-going relationship with relatives and friends and the possibility of playing an active role in society were things which the informants indicated they hope to achieve after the surgery and subsequent weight loss ${ }^{[25]}$.

In terms of health promotion, 18 (58.1\%) respondents stated they seek medical assistance whenever needed and undergo routine checkups. However, $35.4 \%$ of respondents had the nursing diagnosis impaired health seeking behavior, characterized by unawareness and lack of specific actions to promote health, such as: annual examination for prevention of breast, uterine cervix, and prostate cancer; annual dental and ophthalmologic evaluation; and immunization.

Taking into account that 24 (77.4\%) respondents were women and only 9 (37.5\%) of them reported to undergo examinations for the prevention of uterine cervix cancer annually, there's a need for educative activities aimed at promoting the obese women's health.

Therefore, one realizes how fragile these patients are with regard to their health, since, despite provided with information, many of them don't adopt regular health promotion practices, which are crucial for the prevention and early diagnosis of various diseases, that may even be aggravated by obesity or, also, hinder the weight loss process.

Several studies ${ }^{[1-4,6-10]}$ provide evidence for relating obesity to several comorbidities. As these diseases interfere with the health and quality of life of these patients, there's a need for advising on self-care, in order to control and prevent complications related to these pathologies, such as: reducing salt in the diet; weight control; practice scheduled physical exercises; diet change; medication regime; and emotional control. 
From this perspective, patients should be able to identify healthy behaviors leading to a successful weight loss ${ }^{\text {[23] }}$. The prevention of risks to life and well-being of the obese patient should start from the pre-operative phase, with identification and guidance on the risk factors that may lead to compromised health of obese patients ${ }^{[26]}$.

When the patients were asked about the development processes related to obesity, one observed that 13 (41.9\%) respondents reported they have always been obese, 8 (25.8\%) stated they started gaining weight during adolescence, and 10 (32 2\%) experienced this in adulthood.

One identified that impaired adaptation was the most frequent nursing diagnosis (90.3\%) among the patients evaluated. This diagnosis may be attributed to many problems faced on a daily basis by the morbidly obese person, such as social and, also, family prejudice to which he's subject, limitations posed by the disease, hindering the performance of professional activities, and self-image disturbances.

By comparing our results to those of other studies ${ }^{[25]}$, one finds out similarities when a person seeks bariatric surgery because of deviation from health and impaired social life, searches for a stop mechanism for over-eating, or regards surgery as the last resort.

Besides the negative attitudes related to obesity, the presence of other comorbidities associated to excess weight also interferes with the process of human development, leading these patients to reduced expectations and poorer quality of life.

Since they have some comorbidity associated to obesity, 22 (71.0\%) respondents reported they use some kind of medicine on a daily basis. When asked about compliance with the right time to take prescribed medicines, 16 (72.7\%) stated they do that because of the relevance and length of the medicine's effect, resulting in the nursing diagnosis adherence to the medication regime.

Throughout the whole study, one found out that, despite the importance of bariatric surgery for the treatment of obesity and all expectations attributed to this surgical procedure, the nursing diagnosis lack of knowledge on surgery was observed in $32.3 \%$ of participants, as evidenced by the reports of doubts and lack of specific information on bariatric surgery, its complications and postoperative care actions.

Extensive teaching with regard to diet, physical activity, and lifestyle is crucial for helping patients to make the needed changes, achieve and maintain weight loss, and adjust to life after surgery ${ }^{[23]}$. Besides, it’s important that patients are aware that surgery isn't the last resort for a successful outcome. A caregiver's role is encouraging and supporting the patient to get more motivated for complying with his treatment and having realistic expectations with regard to surgery. An educative conversation addressing these issues should take place before surgery ${ }^{[25]}$.

However, usually the patients don't want guidance providing just superficial information on diet, exercise, or medication. This tends to make things worse, leading to increased food intake and decreased self-esteem. Thus, there's a need for training brave nurses and other kinds of health professionals, who dare to conduct an in depth problem analysis, in order to find out what is, in fact, crucial for a morbidly obese patient ${ }^{[8]}$.

Preparing an obese patient for self-care from the preoperative period of bariatric surgery is a must and it aims to improve his quality of life, facilitate his physical, emotional, social, and family adjustment, clarify doubts and fears, develop skills, and favor his rehabilitation after surgery ${ }^{[21]}$.

It's worthy stressing that the nursing diagnoses have a meaning within the nursing process context only if there's a connection between the survey of significant data and the establishment of interventions needed to achieve the expected results ${ }^{[18]}$, and they should be used in order to direct the actions for planning care through a continued evaluation process. 


\section{Conclusion and implications}

To get into the network of care for the obese patient in a conscious way, i.e. competent both from a technical and scientific viewpoint, the nurse should provide his patient with a nursing care effectively confident with regard to the treatment prescribed, which is individualized and humanized.

Knowing the nursing diagnoses of people with morbid obesity undergoing outpatient care allows nurses to plan the care provided to these clientele on an individual basis and contributes to the development and maintenance of self-care abilities. However, for complete nursing care systematization, there's a need for determining the results and testing nursing interventions for each identified diagnosis.

The nursing diagnoses found in this study have no exclusive relation with morbid obesity, they may be found in clients with other chronic diseases.

One hopes this study can contribute to the development of scientific practices in the clinical process adopted to care for patients with morbid obesity, in order to encourage further researches addressing nursing care in this growing practice field.

\section{References}

[1] Burke LE, Wang J. Treatment strategies for overweight and obesity [abstract]. J HYPERLINK "http://www.ncbi.nlm.nih.gov/pubmed/22018175"NursHYPERLINK "http://www.ncbi.nlm.nih.gov/pubmed/22018175" HYPERLINK "http://www.ncbi.nlm.nih.gov/pubmed/22018175"ScholarshHYPERLINK "http://www.ncbi.nlm.nih.gov/pubmed/22018175". 2011 Dec; 43(4): 368-375. http://dx.doi.org/10.1111/j.1547-5069.2011.01424.x.

[2] Brasil. Ministério da Saúde. Plano de ações estratégicas para o enfrentamento das doenças crônicas não transmissíveis (DCNT) no Brasil 2011-2022. Brasília (DF): Ministério da Saúde, 2011. Available from: http://portal.saude.gov.br/portal/arquivos/pdf/cartilha_plano.pdf.

[3] Marcelino LF, Patrício ZM. The complexity of obesity and life after bariatric surgery: a public health issue. Ciênc Saúde Coletiva [Internet]. 2011; 16(12): 4767-4776. Doi: http://dx.doi.org/10.1590/S1413-81232011001300025.

[4] Ide P, Farber ES, Lautz, D. Perioperative nursing care of the bariatric surgical patient. AORN Journal. 2008; 88(1): 30-58. PMid:18677849 http://dx.doi.org/10.1016/j.aorn.2008.02.015

[5] Xeyla R. Saúde reduz idade para cirurgia bariátrica no SUS. 2012. Available from: http://portalsaude.saude.gov.br/portalsaude/noticia/7663/162/ministerio-reduz-idade-minima-\%3Cbr\%3Epara-cirurgia-bariatricano-sus.html.

[6] Owers CE, Abbas Y, Ackroyd R, Barron N, Khan M. Perioperative optimization of patients undergoing bariatric surgery. Journal of Obesity. 2012: 1-6. http://dx.doi.org/10.1155/2012/781546.

[7] Drake DJ, McAuliffe MS, Edge MJ, Lopez CC. Postoperative nursing care of patients after bariatric surgery. Perspectives [Internet]. 6(4). Available from: http://www.perspectivesinnursing.org/pdfs/Perspectives24.pdf.

[8] Kaser N, Kukla A. Weight-loss surgery. OJIN: The Online Journal of Issues in Nursing [Internet]. 2009; 14(1). Available from: www.nursingworld.org/MainMenuCategories/ANAMarketplace/ANAPeriodicals/OJIN/TableofContents/Vol142009/No1Jan09/ Weight-Loss-Surgery.aspx.

[9] Muir M, Heese GA, McLean D, Bodnar S, Rock BL. Handling of the bariatric patient in critical care: a case study of lessons learned. Crit Care Nurs Clin North Am. 2007 Jun; 19(2): 223-240. http://dx.doi.org/10.1016/j.ccell.2007.02.010.

[10] Dybec RB. Intraoperative positioning and care of the obese patient. Plast Surg Nurs. 2004 Jul-Sep; $24(3)$ : 118-122. PMid:15550814

[11] Primo CC, Leite FMC, Amorim MHC, Sipioni RM, Santos SH. Using the international classification for nursing practice in the care of women with mastectomy. Acta Paul Enferm [Internet]. 2010; 23(6): 803-810.

http://dx.doi.org/10.1590/S0103-21002010000600014.

[12] Albuquerque CC, Nóbrega MML, Garcia TR. Terms of the nursing language identified in registers of an uit neonatal. Rev Eletrônica Enferm [Internet]. 2006; 8(3): 336-348. http://www.fen.ufg.br/revista/revista8_3/pdf/v8n3a04.pdf. 
[13] Truppel TC, Meier MJ, Calixto RC, Peruzzo SA, Crozeta K. Systematization of nursing assistance in critical care unit. Rev Bras Enferm [Internet]. 2009; 62(2): 221-227. http://dx.doi.org/10.1590/S0034-71672009000200008.

[14] Conselho Internacional de Enfermeiros. CIPE Versão 2.0: Classificação Internacional para a Prática de Enfermagem. São Paulo: Algol, 2011.

[15] Orem DE, Taylor S. Nursing: concepts of practice. 6. ed. New York: Mosby-Year Book; 2001.

[16] Lata AGB, Albuquerque JG, Carvalho LASBP, Lira ALBC. Diagnósticos enfermería en adultos en tratamiento de hemodiálises. Acta Paul Enferm [Internet]. 2008; 21 Spe: 160-163. http://dx.doi.org/10.1590/S0103-21002008000500004.

[17] Silva ARV, Costa FBC, Araujo TL, Galvão, MTG, Damasceno MMC. Nursing consultation to the patient with diabetes mellitus and arterial hypertension - experience report. Rev RENE. 2007; 8(3): 101-106. Available from: http://www.revistarene.ufc.br/revista/index.php/revista/article/view/678/pdf.

[18] Teixeira CRS, Zanetti ML, Pereira MCA. Nursing diagnoses in people with diabetes mellitus according to Orem's theory of self-care. Acta Paul Enferm [Internet]. 2009; 22(4): 385-391. http://dx.doi.org/10.1590/S0103-21002009000400006.

[19] Cunha GH, Galvão MTG. Nursing diagnoses in patients with Human Immunodeficiency Virus/Acquired Immunodeficiency Syndrome in outpatient care. Acta Paul Enferm [Internet]. 2010; 23(4): 526-532. http://dx.doi.org/10.1590/S0103-21002010000400013.

[20] Felix LG, Soares MMJG, Nóbrega MML. Nursing care protocol to the patient before and after bariatric surgery. Rev Bras Enferm [online]. 2012; 65(1): 83-91. http://dx.doi.org/10.1590/S0034-71672012000100012.

[21] Felix LG, Nóbrega MML, Soares MJGO. Nursing process fundament in the nursing theory of Orem's self-care to a patient submitted to bariatric surgery. Rev Enferm UFPE On Line [Internet]. 2009; 3(4): 26-34. Available from: http://www.ufpe.br/revistaenfermagem/index.php/revista/article/view/89/pdf_944.

[22] Mechanick J, Kushner R, Sugarman H, Gonzalez-Campoy M, Collazo-Clavell M, Guven S, et al. AACE/TOS/ASMBS bariatric surgery guidelines, Endocr Pract [Internet]. 2008; 14 Suppl 1. Available from: https://www.aace.com/files/bariatric.pdf.

[23] Gagnon LE, Sheff EJK. Outcomes and complications after bariatric surgery. Am J Nurs. 2012; 112(9): 26-36. http://dx.doi.org/10.1097/01.NAJ.0000418920.45600.7a.

[24] Brasil. Obesidade. Brasília (DF): Ministério da Saúde, 2006.

[25] Engström M, Wiklund M, Olsén MF, Lönroth H, Forsberg A. The meaning of awaiting bariatric surgery due to morbid obesity. Open Nurs J. 2011; 5: 1-8. http://dx.doi.org/10.2174/1874434601105010001.

[26] Marchi-Alves LM, Nogueira MS, Mendes IAC, Godoy S. Leptin, obesity and hypertension: importance of nursing actions. Acta Paul Enferm [Internet]. 2010; 23(2): 286-290. http://dx.doi.org/10.1590/S0103-21002010000200021. 